TITLE: 3-D Numerical Investigation of the Mantle Dynamics Associated with the Breakup of Pangea

AUTHOR(S): John R. Baumgardner, T-3

SUBMrTted TO: Proceedings of the NATO Advanced Study Institute on "Dynamics Modeling and Flow in the Earth and Planets," University of Alaska, Fairbanks, June 1991 
This report was prepared as an account of work sponsored by an agency of the United States Government. Neither the United States Government nor any agency thereof, nor any of their employees, makes any warranty, express or implied, or assumes any legal liability or responsibility for the accuracy, completeness, or usefulness of any information, apparatus, product, or process disclosed, or represents that its use wuuld not infringe privately owned rights. Reference herein to any specific commercial product, process, or service by trade name, trademark, manufacturer, or otherwise does not necessarily constitute or imply its endorsement, recommendation, or favoring by the United States Government or any agency thereof. The views and opinions of authors expressed herein do net necessarily state or reflect those of the United States Government or any agency thercof.

\title{
3-D NUME!ICAL INVESTIGATION OF THE MANTLE DYNAMICS ASSOCIATED WITH THE BREAKUP OF PANGEA
}

\author{
JOHN R. BAUMGARDNER \\ MS B-216 \\ Los Alamos National Laboraton \\ Los Alamos, New Mexico 87545, U.S.A.
}

\begin{abstract}
Three-dimensional finite element calculations in spherical geometry are performed to study the response of the mantle with platelike blocks : its surface to an initial condition corresponding to subduction along the margins of Pangea. The ma $\ldots$. . treated as an infinite Prandtl number Boussinesq fluid inside a spherical shell with isothermal, unat iormable, free-slip boundaries. Nonsubducting, rigid blocks to model continental lithosphere are included $n$ the topmost layer of the computational mesh. At the beginning of the numerical experiments these blo es repsesent the present continents mapped to their approxima'e Pangean positions. Asymmetrical downwelling at the margins of these nonsubducting blocks results in a pattern of stresses that acts to pull the supercontinent apar. The calculations suggest that the breakup of Dangea and the subsequent global pattern of seafloor spreading was driven largely by the subduction at the Pangean margins.
\end{abstract}

\section{Introduction}

A question persisting from the early days of plate tectonics has been what pattern of flow in the mantle is responsible for the breakup of Pangea and the subsequent migration of most of the fragments toward the Pacific hemisphere. Analytical and numerical studies of thermal convection in spherical shells (Chandrasekhar, 1961; Zehib et al., 1983; Baumgardner, 1983. 1985, 1988; Bercovici et al., 1989) indicate that for whole mantle convection, harmonic degrees three and higher should prevail. Current plate motions, however, display strong degree one and two comsonents (Peltier, 1985). Seismic tomography studies (Ciayton and Comer, 1983; Dziewonski, 1984; Dziewonski and Woodhouse, 1987; Inoue et al., 1990) also indicate a strong degree two component in the lower mantle's seismic velocity structure. This low degree pattern for the lower mantle is a robust feature of essentially all global seismic models (Fig. 1). Similarly, the non-hydrostatic geoid contains a large degree two component (Chase and Sprowl, 1983). A key to resolving this differen,e berween convection models and the actual obse:vational data seems to be that the mantle's stiff upper boundary layer, the lithosphere, plays a critical role in the inantle's overali dynamics (Christiansen, 1985; Davies, 1988a; Ournis, 1988, 1990, 1991) and is largely responsible for enforcing the observed low degree betavior. The details of the coupling and interastions between the lithosphere and deeper mantle are as yet, however, far from being understood.

Current generation computers are providing the capabilities to perform three-dimensional dynamic simulations (Baumgardner, 1988; Glatzinaier, 1988; Bercovici et al., 1989a) of the resolution and sophistication required to address such issues. This paper dcscribes a 

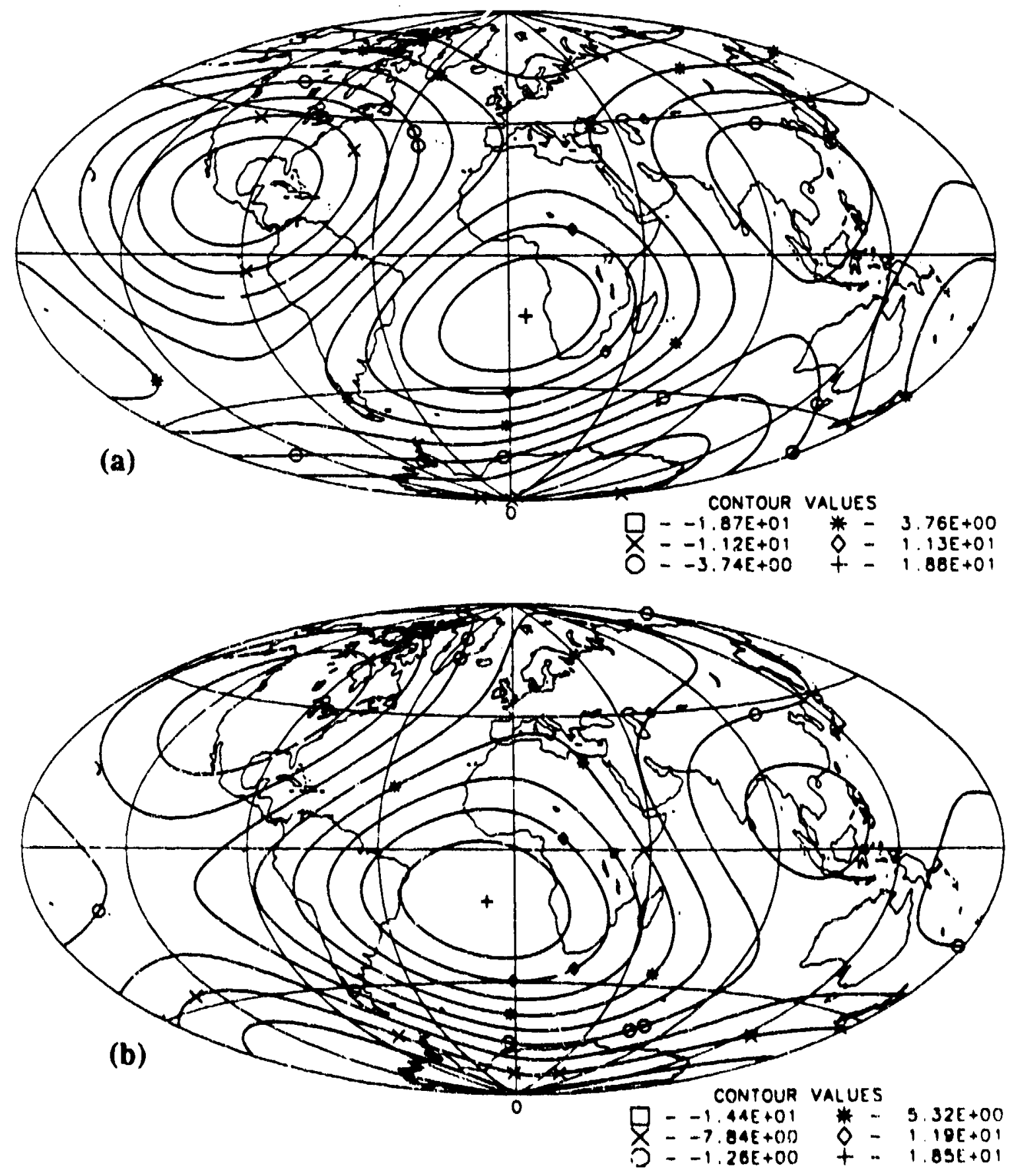

Figure 1. Vertically integrated lower mantle P-wave slowness variations for harmonic degrees up to 3 from seismic tomography mudels of (a) Dziewonski and Woodhouse (1987) and (b) Clayton and Comer (1983). Note similarity of tw'o models with maximum slowness beneath the south Atlantic and slowness minima beneath North America. Antarctic, and southeast Asia. 


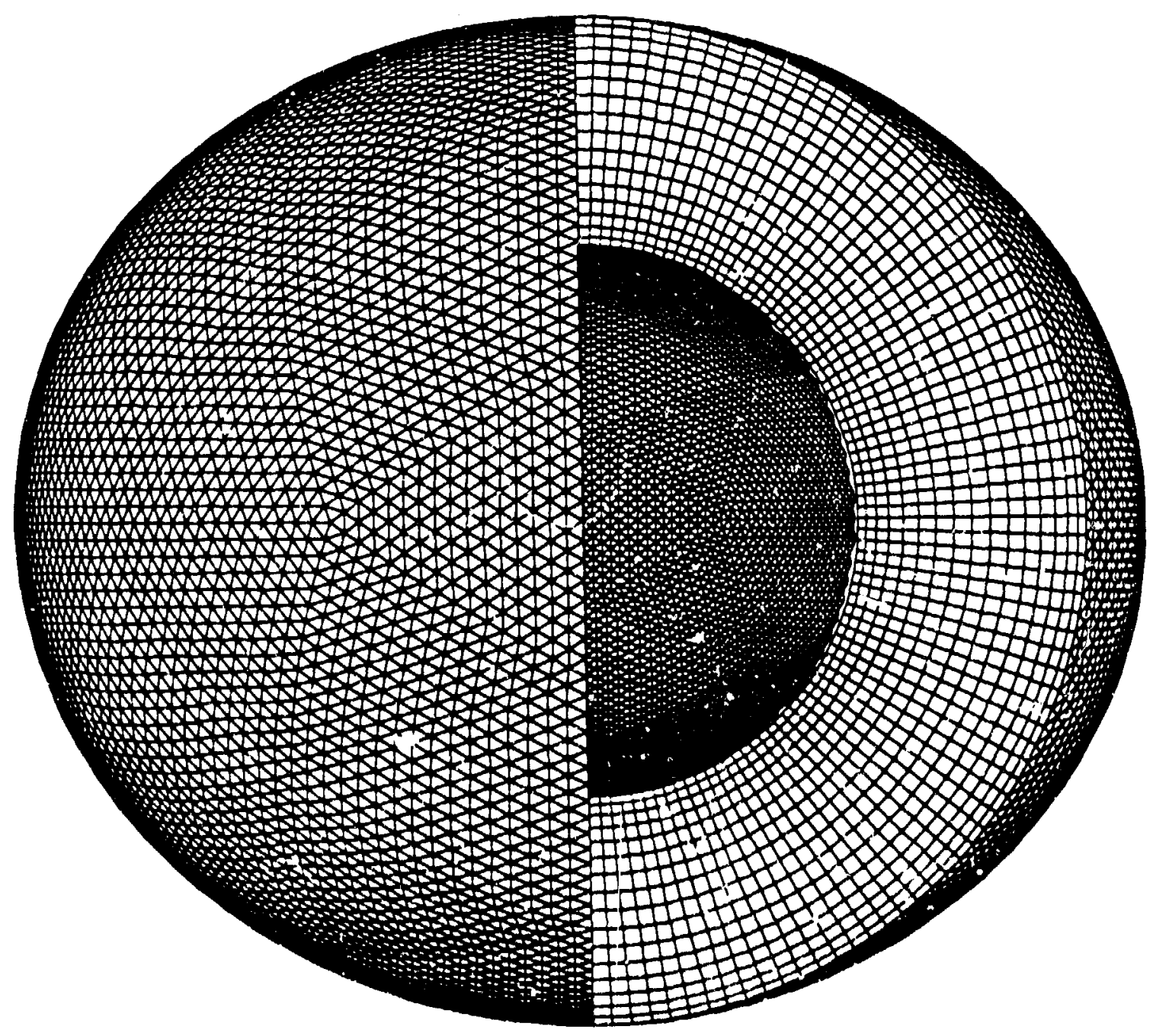

Figure 2. Finite element mesh used for the numerical model of the earth's mantle, with section removed 10 display the interior. Mesh consists of 17 layers of 10242 nodes each. Nonuniform thickness of layers in radial direction provides $100 \mathrm{~km}$ resolution at the boundaries. Lateral resolution at the top boundary is $250 \mathrm{~km}$.

numerical experiment performed on a Cray Y-MP using the spherical finite ternent multigrid code TERRA. The experiment was aimed at investigating the effects of rigid patches, or plates, at the surface on the convecting system. Special initial conditions were chosen to model subduction at the margins of a supercontinent that is comprised of rigid subunits and has a geometry resembling that of Pangea. 


\section{Mathematical Formulation}

The earth's mantle in this experiment is modeled as an irrotational, infinite Prandtl number, constant viscosity, linear Boussinesq fluid within a spherical shell with isothermal, undeformable, free-slip boundaries. Under these conditions the following equations describe the local fluid behavior:

$$
\begin{gathered}
\mu \nabla^{2} u=\nabla p+\alpha\left(T-T_{0}\right) P_{0} g \\
\nabla \cdot u=0 \\
\frac{\partial T}{\partial t}=-\nabla \cdot(T u)+[\nabla \cdot(k \nabla T)+H] / P_{0} c_{v}
\end{gathered}
$$

Here u denotes fluid velocity, $\mathrm{p}$ pressure, $\mathrm{T}$ absolute temperature, $\mu$ dynamic viscosity, $\alpha$ volume coefficient of thermal expansion. To reference temperature, po density, 8 gravitational acceleration, $k$ thermal conductivity, $H$ specific radiogenic seat production rate, and $c_{v}$ specific heat at constant volume.

Rigid plates are included in this framework in a simple manner by adding forces to the right hand side of Eq. (1) that yieid rigid rotation of each plate about a Euler pole such that the net torque on the plate is zero. These forces are obtained by first applying Newton's method to find the rotation vector $\omega$ that results in zero net torque $\tau$ on the plate. By taking small variations in $\omega$ about the $x-, y-$, and $z$-axes, one can compute $\partial \tau / \partial \omega$ and then modify $\omega$ by subtracting $\tau /(\partial \tau / \partial \omega)$ such that $\tau$ approaches zero. By creating a temporary velocity field $v$ that is equal to $u$ outside the volume of the plates but which has the rigid rotations within the plates, the force field, given by $r^{*}=\mu \nabla^{2} v$, required to produce the strain field implied by $v$ can readily be computed. These forces are added to the right hand side of Eq. (1) at the nodes enveloping and including each plate without altering the larger solution method or the boundary conditions. Other approaches for treating surface plates are described by Gable et al. (1991), King et al. (1992), and Weinstein et al. (1992).

\section{Numerical Approach}

The fluid equations are solved using the finite element method on a mesh constructed from the regular icosuhedron (Fig. 2). The elements have the form of triangular prisms. Piecewise linear spherical finite element tasis functions provide second-order spatial accuracy (Baumgardner. 1983; Baumgardner and Frederickson, 1985). The mesh has 10242 nodes in each of 17 radial layers. The 160 nodes around the equator imply a tangential spatial resolution at the outer surface of $250 \mathrm{~km}$. Nonuniform spacing of nodes in the radial direction assists in resolving the boundary layers.

The calculational procedure on each time step is first to apply a two-level conjugate gradient algorithm (Ramage and Wathen, 1992) to solve for the velocity and pressure fields simultanenusly from Eq. (1) and (2) and then to update the temperature field according to 
Eq. (3) using a forward-in-time interpolated donor cell advection scheme. An iterative multigrid solver (Baumgardner, 1983) is employed inside the conjugate gradient procedure, and its high rate of convergence is responsible for the method's overall efficiency. The finite element operators are used for all the gradient and divergence terms in Eq. (1)-(3) except for the heat conduction, which employs a finite difference technique. A particle method is used to define the plate locations and to track their motions. Four particles per node are used to represent the plate Jistribution. Piecewise linear basis functions are employed to map particle data to the nodes. The particles are moved in a Lagrangian manner at each time siep using the piecewise linear basis functions to interpolate the nodal velocities to the particles. The advantage of this particle method is low numerical diffusion and hence the ability to minimize the smearing of the plate edges.

\section{Parameterization}

The Boussinesq approximation yields a model for the mantle that involves but a few. parameters, as is evident from Eq. (1)-(3). However, because computational costs preclude calculations with spatial resolution sufficient to treat the dynamics at the actual Rayleigh numbers appropriate to the earth, it was necessary to scale some of the parameters to give less vigorous convection. The choice made in this study was to scale the thermal conductivity $k$ ond the radiogenic heat production rate $\mathrm{H}$ to larger values to reduce the effective Rayleigh number to what could be treated with the mesh resolution described earlier. The scaling factor selected was 6.25. A benefit of this scaling is that velocities and time scales can approximate thuse of the physical earth. Values for the other parameters then were chosen as suitable estimates for the actual earth within the limitations of the Boussinesq formulation.

Parameters that relate to the thermal aspects of the model include the boundary iemperatures, the thermal conductivit\%, the radiogenic heating rate, the volume coefficient of thermal expansion, and the specific heat. Temperatures chosen lor the top and bottom boundaries were $300 \mathrm{~K}$ and $2300 \mathrm{~K}$, respectively. For the earth this implies a bottom temperature of about $3200 \mathrm{~K}$ if one takes typical estimate for the adiabatic temperature drop across the manile of $900 \mathrm{~K}$. Choice of this relatively low bottom bounda y temperature is influenced by observatior.s that the heat flux associated with hot spots is a small fraction of the earth's total hert flux (Davies, 1988b) and that the temperature anomalies in the hot spots themselves appear to be only on the order of $200-300 \mathrm{~K}$ (Richards et al., 1988). Since previous modeling has shown that most of the base heating of the mantle is transported to the surface by plumes (Baumgardner, 1985; Bercovici et al., 1989b), it is inferred that the fraction of the total heating from the core is probably small and that most of the heating is due to internal radioactivity. Consistent with this conclusion is the choice of an unscaled radiogenic heating rate of $5 \times 10^{-12} \mathrm{~W} \mathrm{~kg}^{-1}$ (which translates to about $40 \mathrm{~mW} \mathrm{~m}^{-2}$ of surface heat flux). The unscaled thermal conductivity is assumed constant through the mantle at a value of $4.0 \mathrm{~W} \mathrm{~m}^{-1} \mathrm{~K}^{-1}$. The volume coefficient of thermal expansion was chosen to be $2.5 \times 10^{-5} \mathrm{~K}^{-1}$ and the specific heat was taken io be $1000 \mathrm{~J} \mathrm{~kg}^{-1} \mathrm{~K}^{-1}$. The inean temperature of the computational domain was used as the reference temperature $\mathrm{T}_{0}$. The density was chosen to be $4500 \mathrm{~kg} \mathrm{~m}-3$. The gravitational acceleration $10 \mathrm{~m} \mathrm{~s}^{-2}$, and the dynamic viscosity $1.5 \times 10^{22} \mathrm{~Pa} \mathrm{~s}$. 

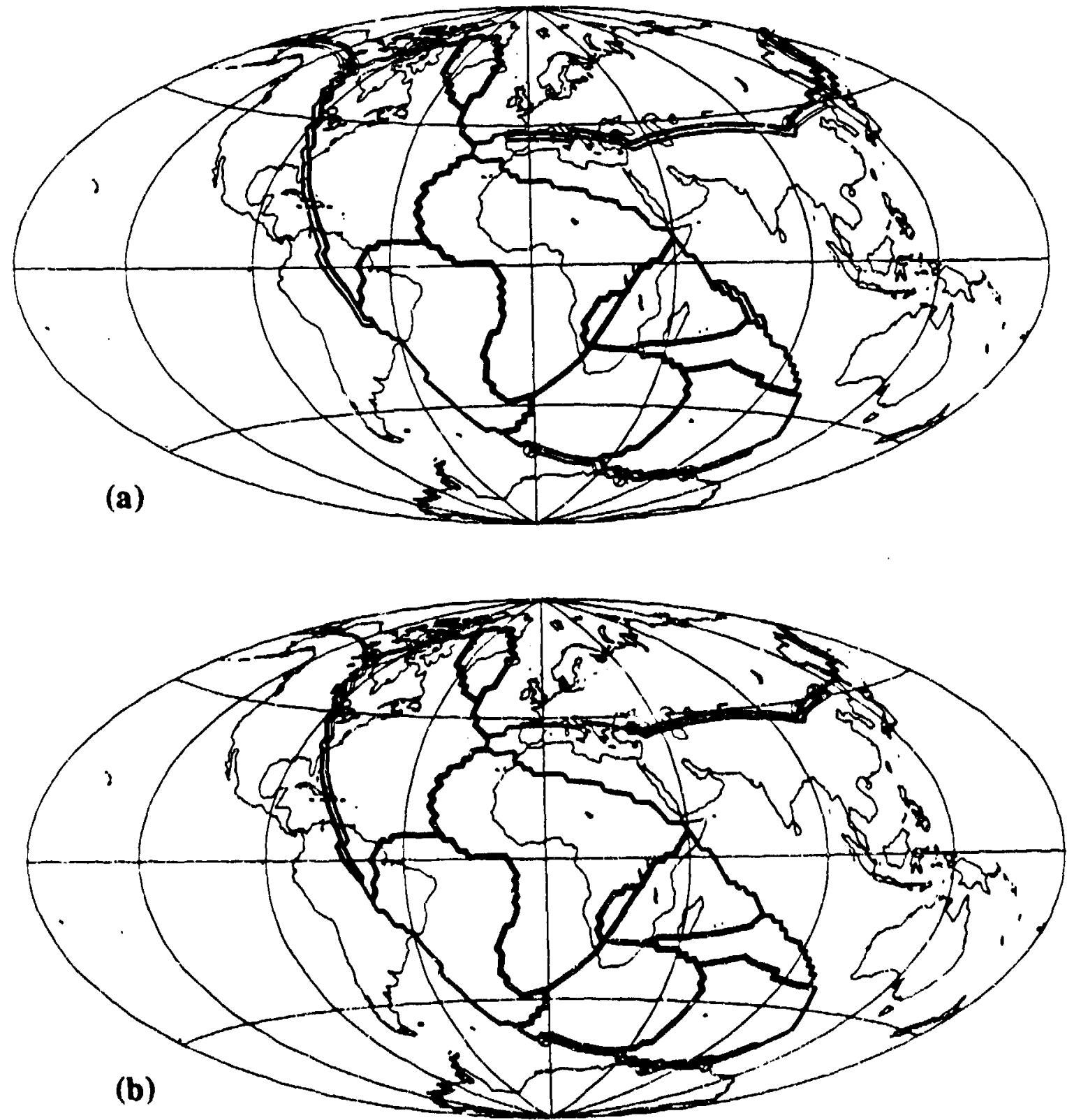

Figure 3. Initial configuration of continental blocks with fine contours representing the slablike temperature perturbations at (a) $250 \mathrm{~km}$ depth and (b) $1000 \mathrm{~km}$ depth. Magnitude of the temperature perturbations is $-400 \mathrm{~K}$. The fine contour lines represent $33 \%$ and $67 \%$ of the peak value. Outlines of present day shorelines are included for reference. 


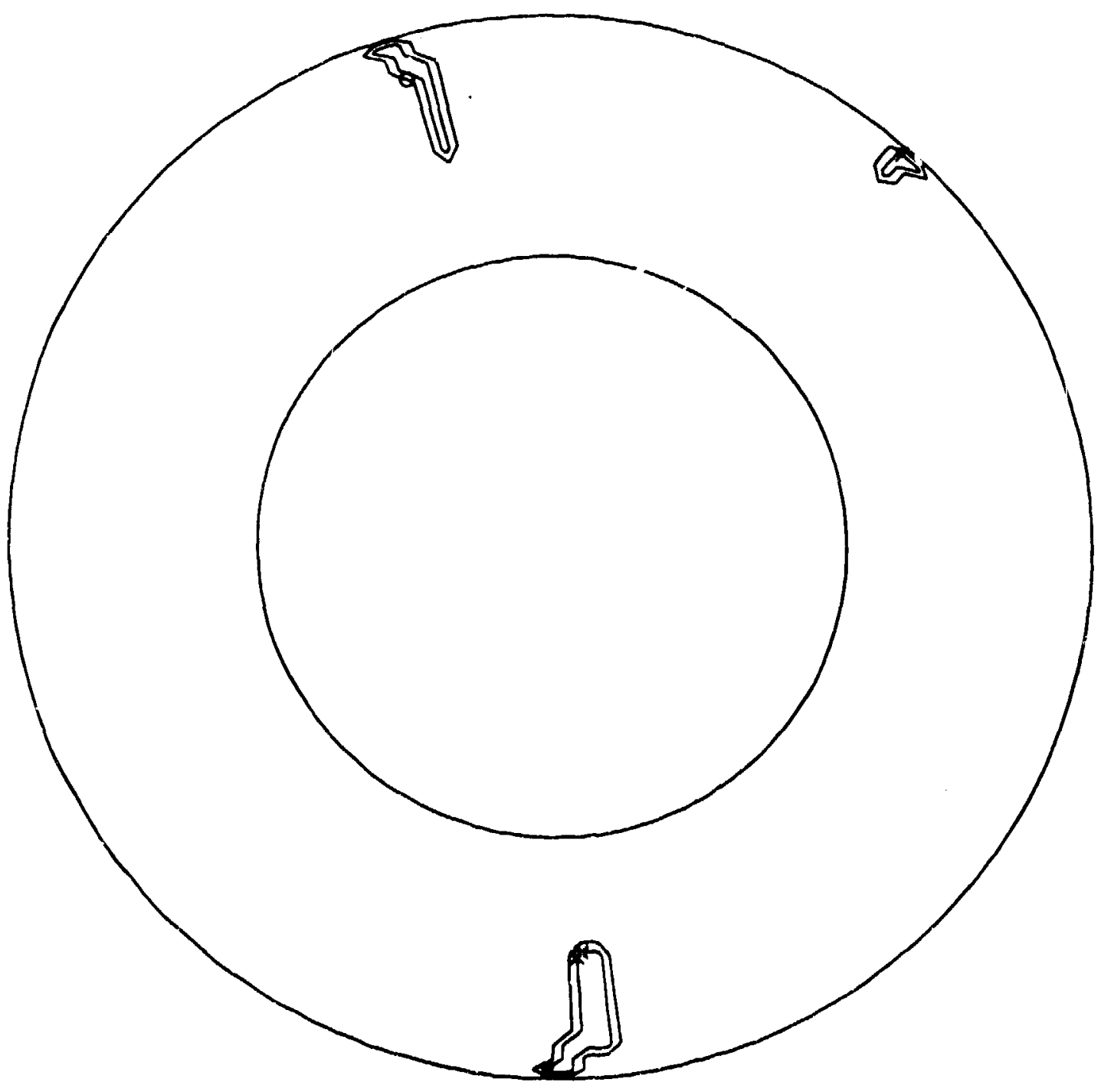

Figure 4. Cross-section through the spherical shell showing the initial slablike temperature perturbations. Contour values are $-100 \mathrm{~K}$ and $-300 \mathrm{~K}$ relative to the mean value at a given radius. Shape at 6 o'clock is wider because section slices obliquely through the perturbation.

\section{Initial Conditions}

To explore the conjecture that subduction at the margins of Pangea might be related to the fashion in which Pangea rifted and its fragments drifted apart, a set of slablikc initial teimperature perturbations is prescribed to represent circum-Pangea subduction. The perturbations have an amplitude of $400 \mathrm{~K}$, a width that crrresponds to a single finite element basis function (about $250 \mathrm{~km}$ ), and depths that assiune values cf either 315 or $1450 \mathrm{~km}$. 
They lie at the margin of the reconstruction of Pangea displayed in Fig. 3 with the distributions at the two depth ranges shown separately in Fig. 3a and Fig. 3b. A crosssectional view of these perturbations is given in Fig. 4. The inclusion of the deeper cold perturbation is motivatzd in part by the seismic tomography results for the lower mantle that suggest distinct regions of high P-wave velocity beneath North America, Antarctica, and southeast Asia as indicated in Fig. 1. In addition to the cold slablike perturbations in the upper half of the spherical shell, four circular warm perturbations are introduced in the lower half of the shell as indicated in Fig. 5. These perturbations are Gaussian in shape and have 2 peak amplitude of $50 \mathrm{~K}$.

The definition of the individual continental blocks is also provided in Fig. 3. These represent the present continental areas mapped to their estimated Pangean locations. Initially the North American, Greenland, and Eurasian blocks are constrained to have a common rotation vector. Similarly, the South American, African, and Miadagascar blocks initiaily rotate as a singic unit. Likewise the remaining four blocks initially have a common rotation vector. Later in the course of the calculation, these composite blocks are allowed to break into constituent parts with separate rigid motions.

Since the velocity and pressure fields are computed together from the temperature field according to Eq. (1) and (2), no initial specificaticin of velocity or pressure is needed. The initial state then consists of a relatively blank mantie as far as its temperature structure is concerned. Upon the spherically symmetric radial temperature profile of Fig. 6 with its large boundary gradients there is imposed the pattern of cold slablike perturbations in the upper haif of the shell shown in Figs. 3 and 4 and the distribution of warm columns in the lower half of the shell as displayed in Fig. 5.

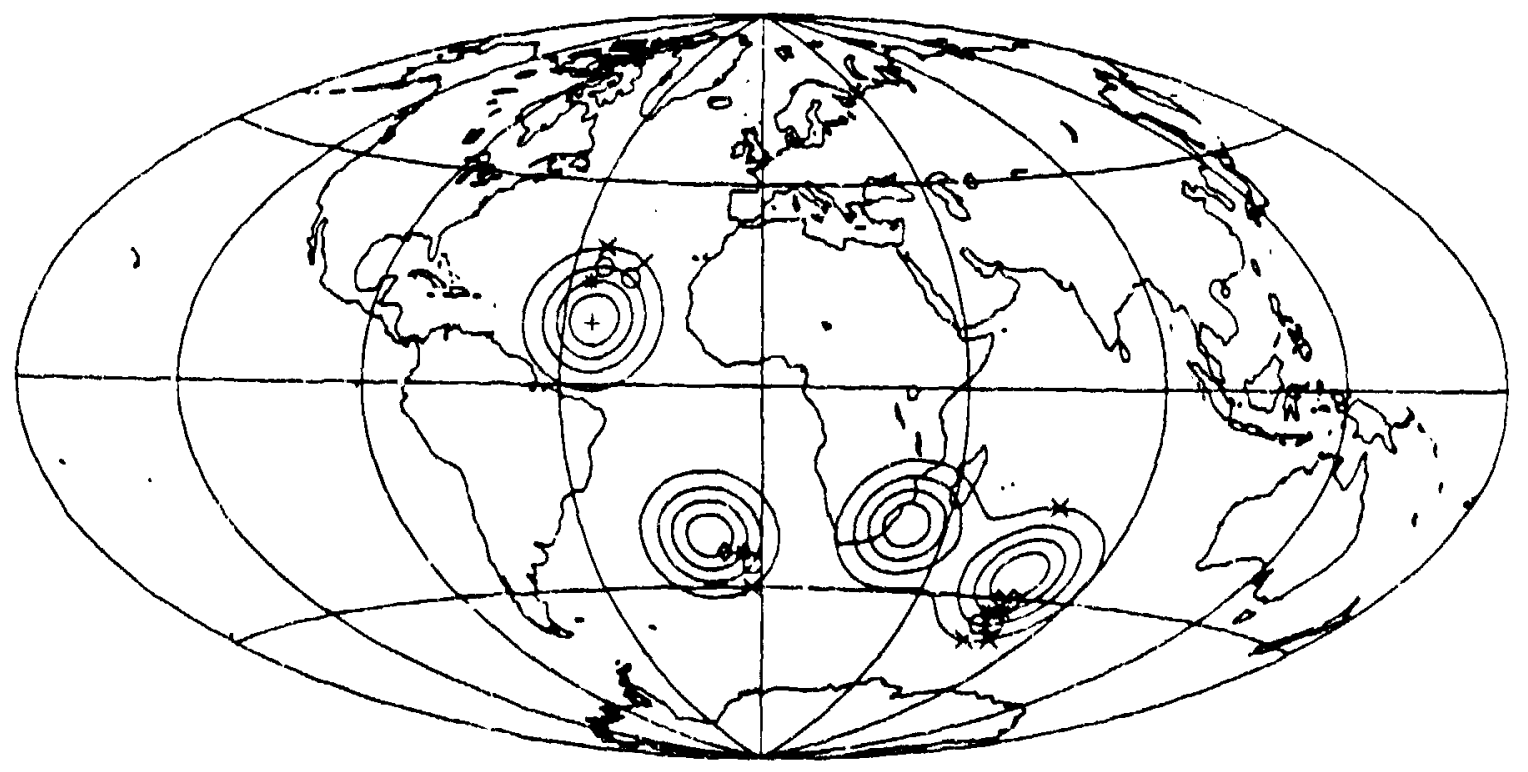

Figure 5. Initial temperature perturbations between $1445 \mathrm{~km}$ depth and bottom of the shell. Distributions are Gaussian in shape and have a peak value of $50 \mathrm{~K}$. Contours are $10 \mathrm{~K}$ apart. 


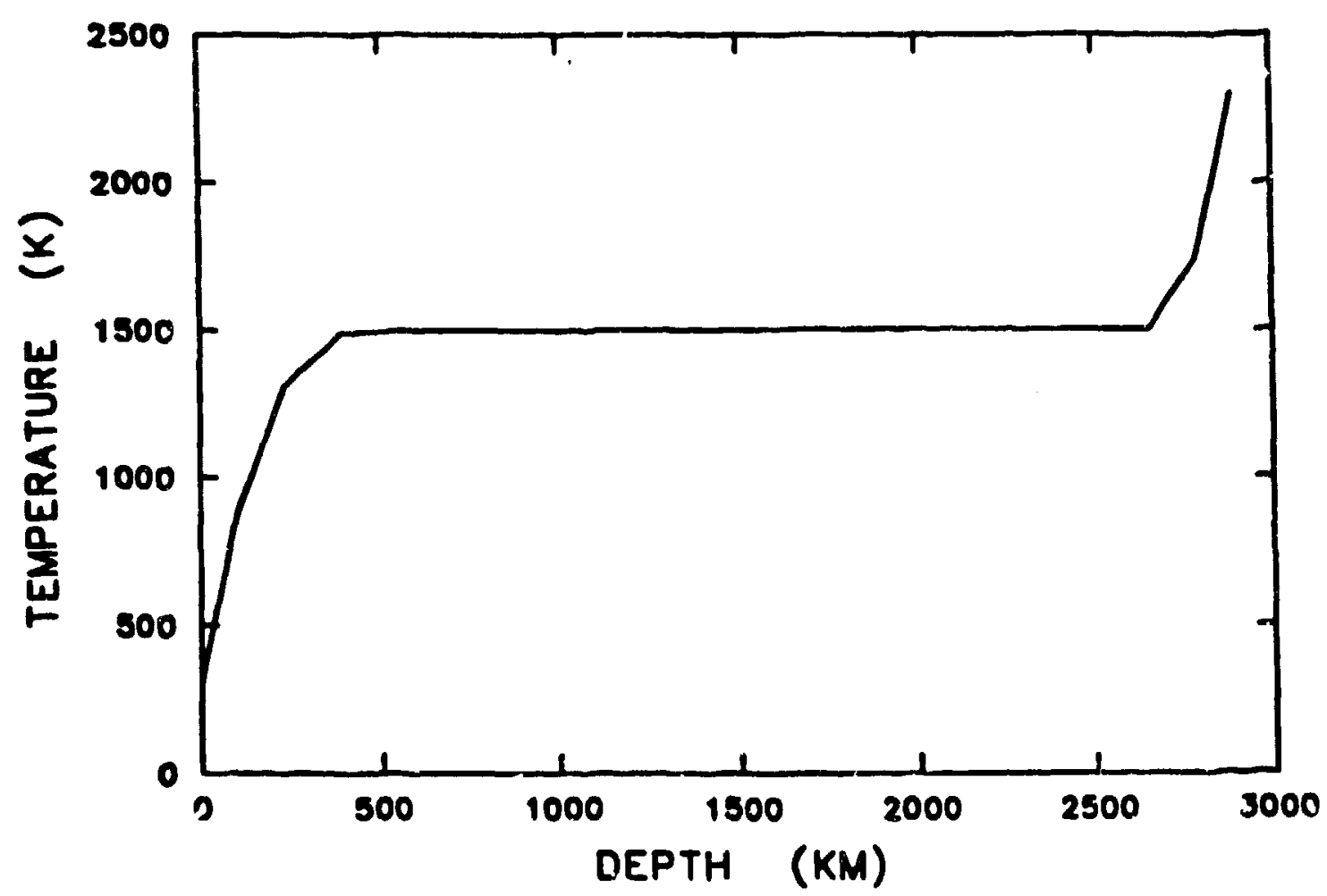

Figure 6. Spherically averaged initial radial temperature profile.

\section{Results}

Fig. 7 contains a sequence of snapshots at times of 20,40,60, and 80 Myr showing the locations of the continental blocks and the veiocities at the surface of the spherical shell. A notable feature in the velocity fields of Fig. 7 is the motion of the nonsubducting blocks toward the adjacent zones of downwelling flow. This motion is primarily a consequence of the drag exerted on a nonsubducting block by the material below it as this material drifts toward the downwelling zone. Such a general pattern of flow is evident in the cross-sectional slices of Fig. 8. The translation of a nonsubducting block in this manner leads to a backward. or oceanward, migration of the location of the downwelling. This oceanward translation of the continental blocks and subduction zones therefore acts to pull the supercontinent apart. This behavior is a oasic fluid mechanical result and not the consequence of any special initial conditions or unusual geometrical specirications other than the asymmetrical downwelling at the edge of a nonsubducting portion of the surface.

That the blocks move apart without colliding and overrunning one another, on the other hand, depends very strongly on the initial distribution of thermal perturbations, the shapes of the blocks, and timing of their breakup. A moderate amount of trial and error was involyed in finding the special set of conditions that leads to the results shown in Fig. 7 and 8 . This 
experience suggests that it should be possible to reconstruct the state of the mantle in the early Mesozoic or earlier from present day observationa! data and a sufficiently realistic forward numerical model. Clearly the calculations reported here suffer from inadequate spatial resolution, from the lack of variable viscosity effects, and from no platelike treatment of the ocean portions of the surface. Adding platelike behavior to the oceanic parts of the surface, for example, would no doubt improve the tendency for the Indian block to be dragged northward toward the subduction zone on the south margin of Asia and for the Sumatra and Australian blocks also to be rafted northward toward the subduction zones of the southwest Pacific. These numerical challenges appear to be readily addressable within the present finite element framework with the resources available on existing parallel machines.

The distribution of cold material in the lower mantle follows what would be expected from the initial temperature field. Fig. 9 shows contours of temperature at a depth of $2790 \mathrm{~km}$, or $100 \mathrm{~km}$ above the bottom shell boundary, at a time of $60 \mathrm{Myr}$. Broad cold areas lie below the narrow zones of deep cold initial temperatures beneath the Americas. Antarctica, and south central Asia. There is also a conjunction of three belts of warm temperatures bencath the south Atlantic. This distribution of temperatures displays a qualitative similarity with the seismic tomography models of Fig. 1. A higher viscosity lower mantle, as opposed to the constant viscosity case presented here, would yield more sluggist. lower mantle velocities and a longer integration time for cold descending flow. This is a plausible explanation for the good correlation between present day lower mantle seismic velocities and past subduction patterns (Richards and Engebretson, 1992).

\section{Conclusions}

Numerical 3-D global modeling of the earth's mantle and lithosphere is reaching enough maturity to begin testing some ideas about the earth's tectonic history. The numerical experiment reported here suggests that the essential physics associated with the breakup of Pangea was the buoyancy and strength of the continental lithosphere. The fact that continental lithosphere has sufficient buoyancy to resist subduction and sufficient strength to resist significant lateral deformation arising from drag forces at its base means that blocks of continental lithosphere tend to be dragged toward nearby zones of downivelling flow and then tend to override such zones. These basic fluid mechanics principles imply that st'zduction along the margins of Z̈angea naturally results in the tendency for Pangea to be pulled apart. The observational avidence that subduction zones today ring much of what was formerly the Pangean margin, that vast geosynclinal troughs of sediments also reside on this former Pangean margin, and that seismic tomography reveals oroad zones of high velocity material reside in the lower mantle beneath major segments of the Pangean margin supports the general thesis that persisting subduction through the Mesozoic and Cenozoic, primarily along this evolving margin, is largely responsible for the observed plate motions and pattern of seafloor spreading during this recent portion of earth history. These arguments also imply that the lithosphere plays a crucial role in the overall dynamics of the earth's interior. Finally, the prospect; for greatly improved 3-D numerical modeling of this strongly nonlinear system by exploiting the machine resources now available in paralle! supercomputers suggest fruitful opportunities for research in many areas of earth science lie ahead. 

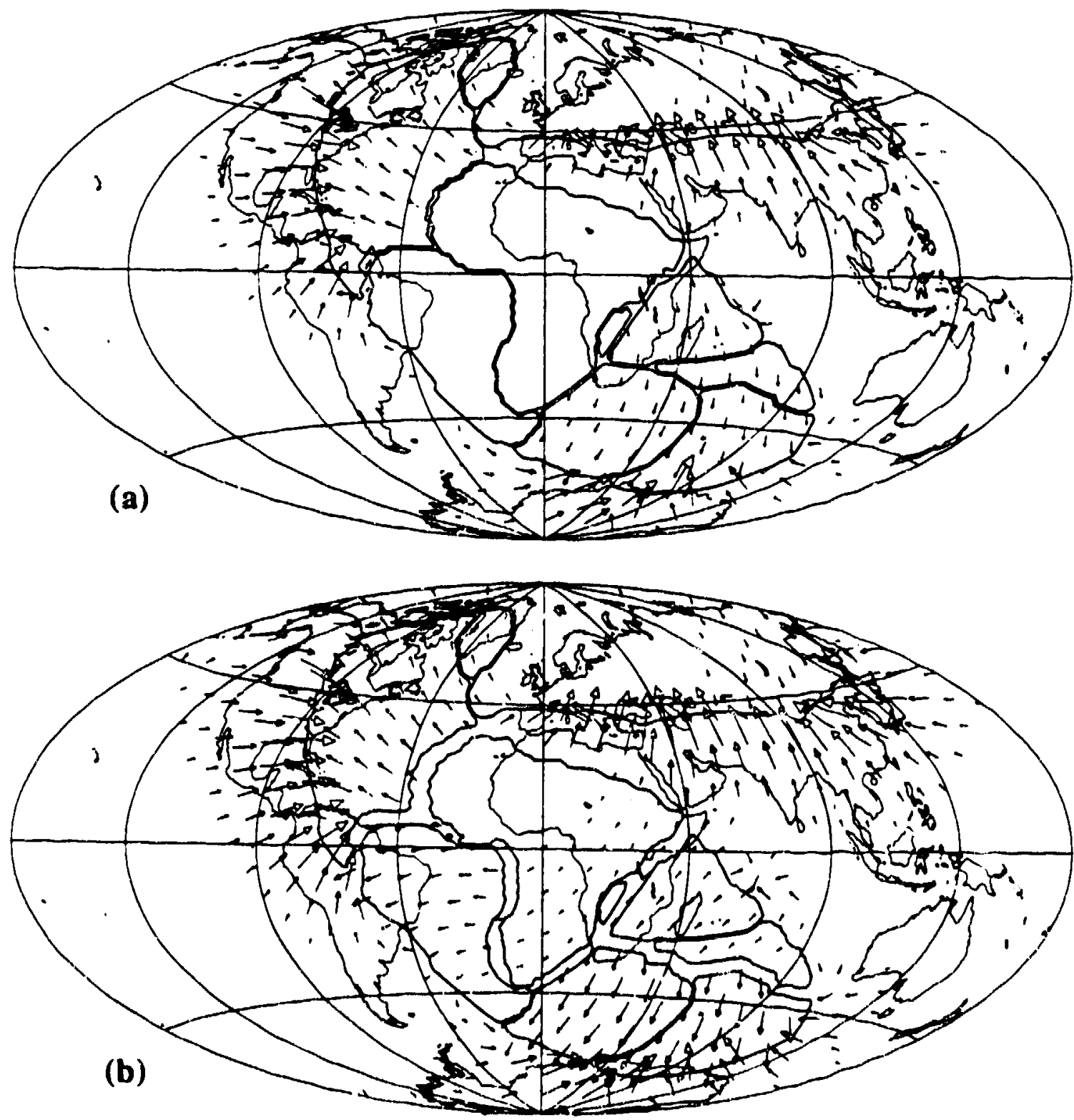

Figure 7. Surface velocities and positions of continental biocks at (a) $20 \mathrm{Myr}$, (b) $40 \mathrm{Myr}$, (c) $60 \mathrm{Myr}$, and (d) $80 \mathrm{Myr}$. Arrows are scaled with the maximum velocity equal to $5.36 \mathrm{~cm} / \mathrm{yr}$ in (a), $7.05 \mathrm{~cm} / \mathrm{yr}$ in (b), $7.25 \mathrm{~cm} / \mathrm{yr}$ in (c), and $8.17 \mathrm{~cm} / \mathrm{yr}$ in (d). 

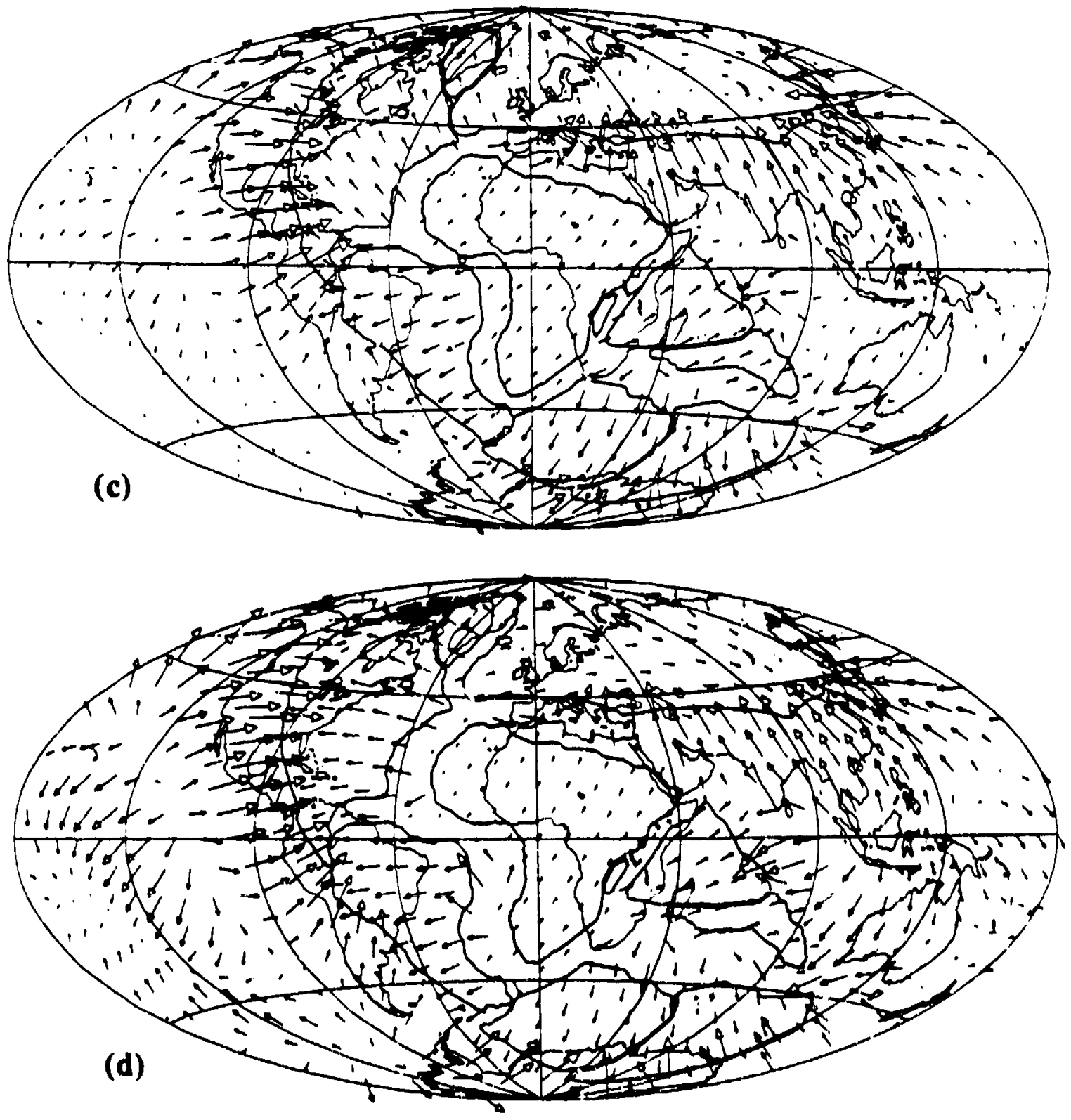

Figure 7. Continued. 


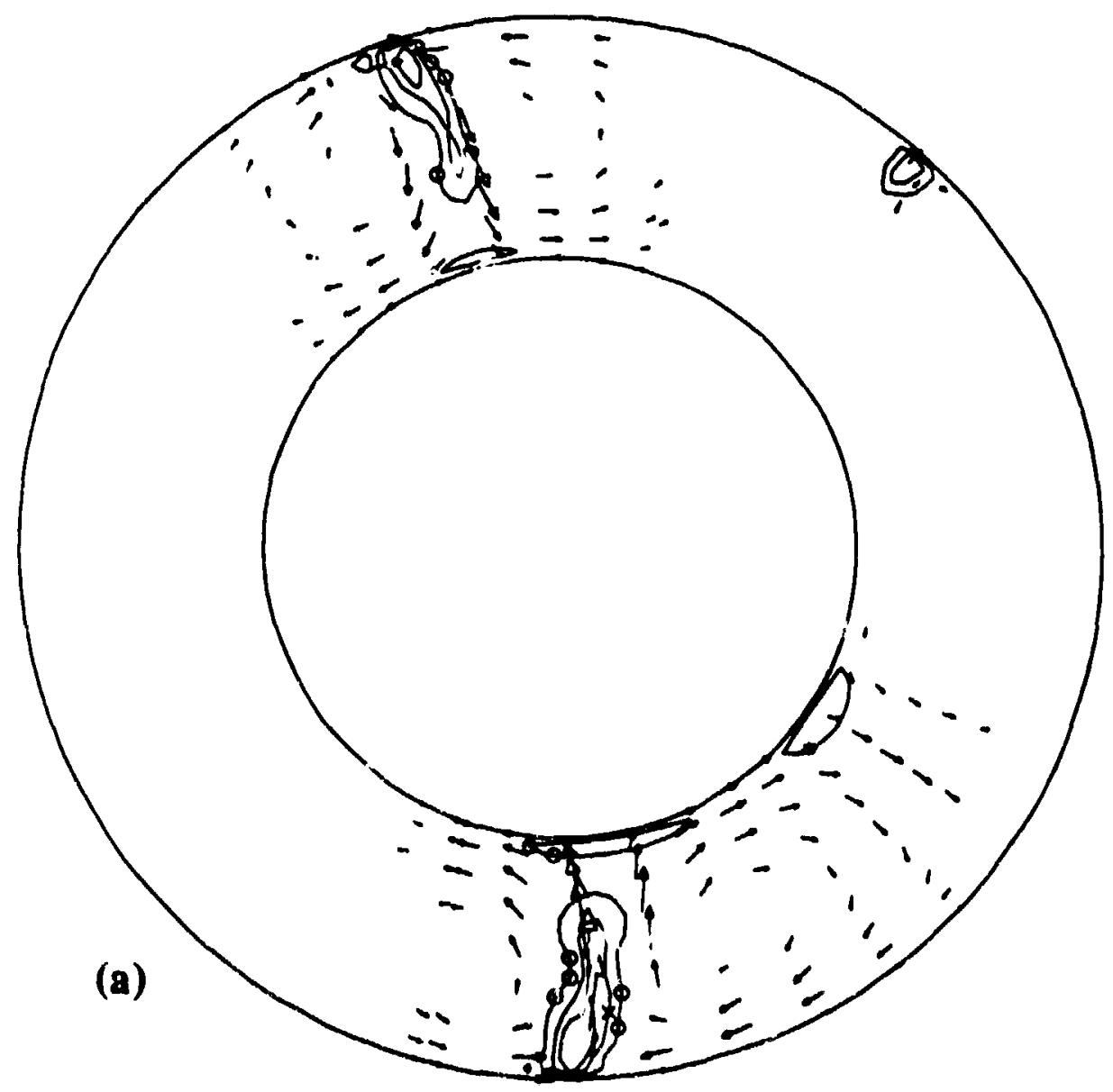

Figure 8. Cross-sectional slices showing temperature deviations from the mean radial value and components of velocity in the plane of the slice at (a) $20 \mathrm{Myr}$, (b) $40 \mathrm{Myr}$, (c) $60 \mathrm{Myr}$, and (d) $80 \mathrm{Myr}$. Teniperature contours are marked wich squares for the $-500 \mathrm{~K}$ contour, ' $\mathrm{x}$ ' for the $-300 \mathrm{~K}$ contour, ' 0 ' for the $-100 \mathrm{~K}$ contour, ' for the $+100 \mathrm{~K}$ contour, diamonds for the $+300 \mathrm{~K}$ contour, and ' + ' for the +500 contour. Arrows are scaled with she maximum velocity equal to $7.44 \mathrm{~cm} / \mathrm{yr}$ in (a), $13.9 \mathrm{~cm} / \mathrm{yr}$ in (b), $18.0 \mathrm{~cm} / \mathrm{yr}$ in (c), and $18.2 \mathrm{~cm} / \mathrm{yr}$ in (d). Downwelling flow at 11 o'clock is off the west coust of North America, at 2 o'clock is north of Africa, and at 6 o'cluck is in the Antarctic. The upwelling at 4 o'clock is in the south Indian Ocean. 


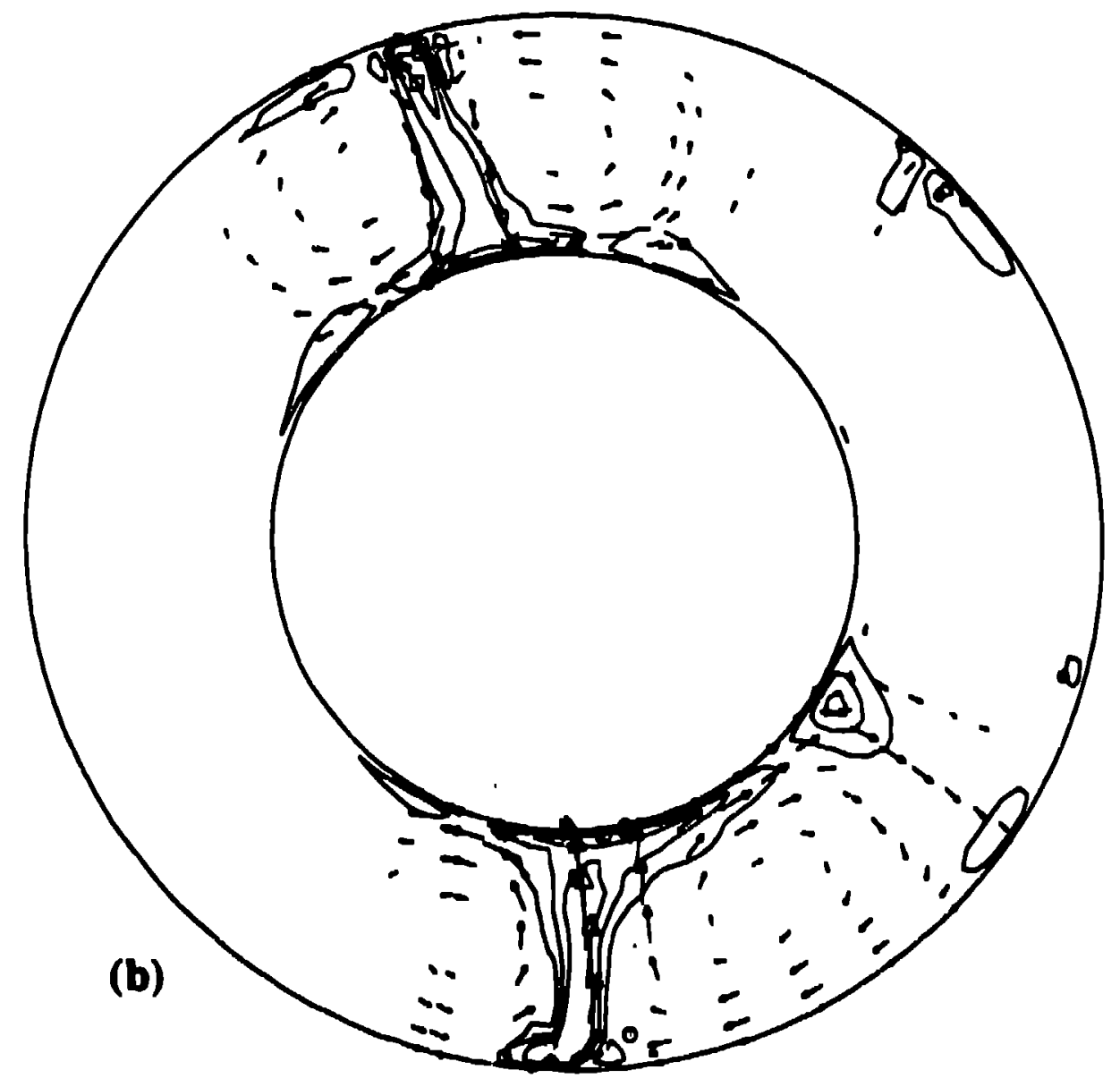

Figure 8. Continued. 


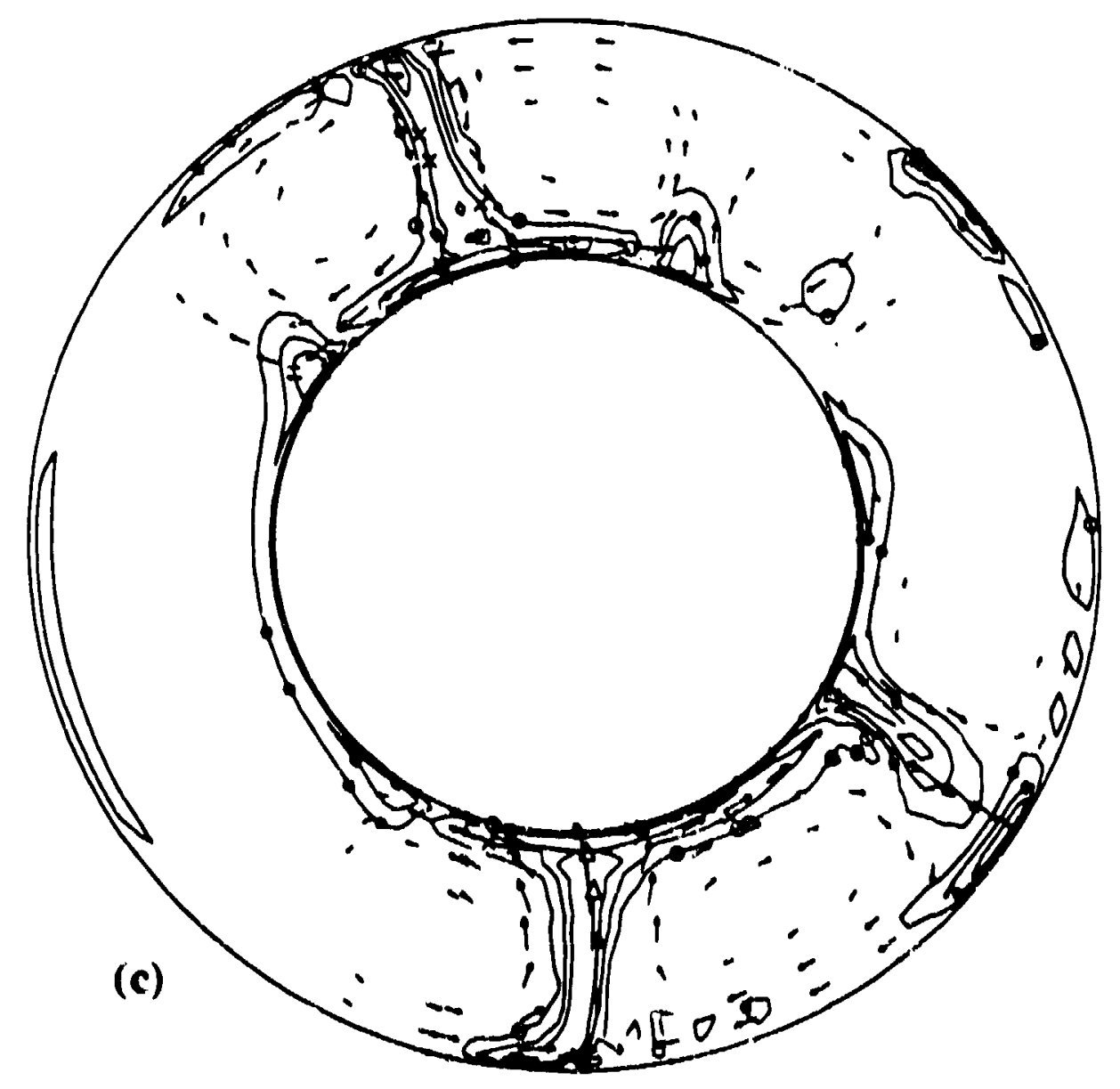

Figure 8. Continued. 


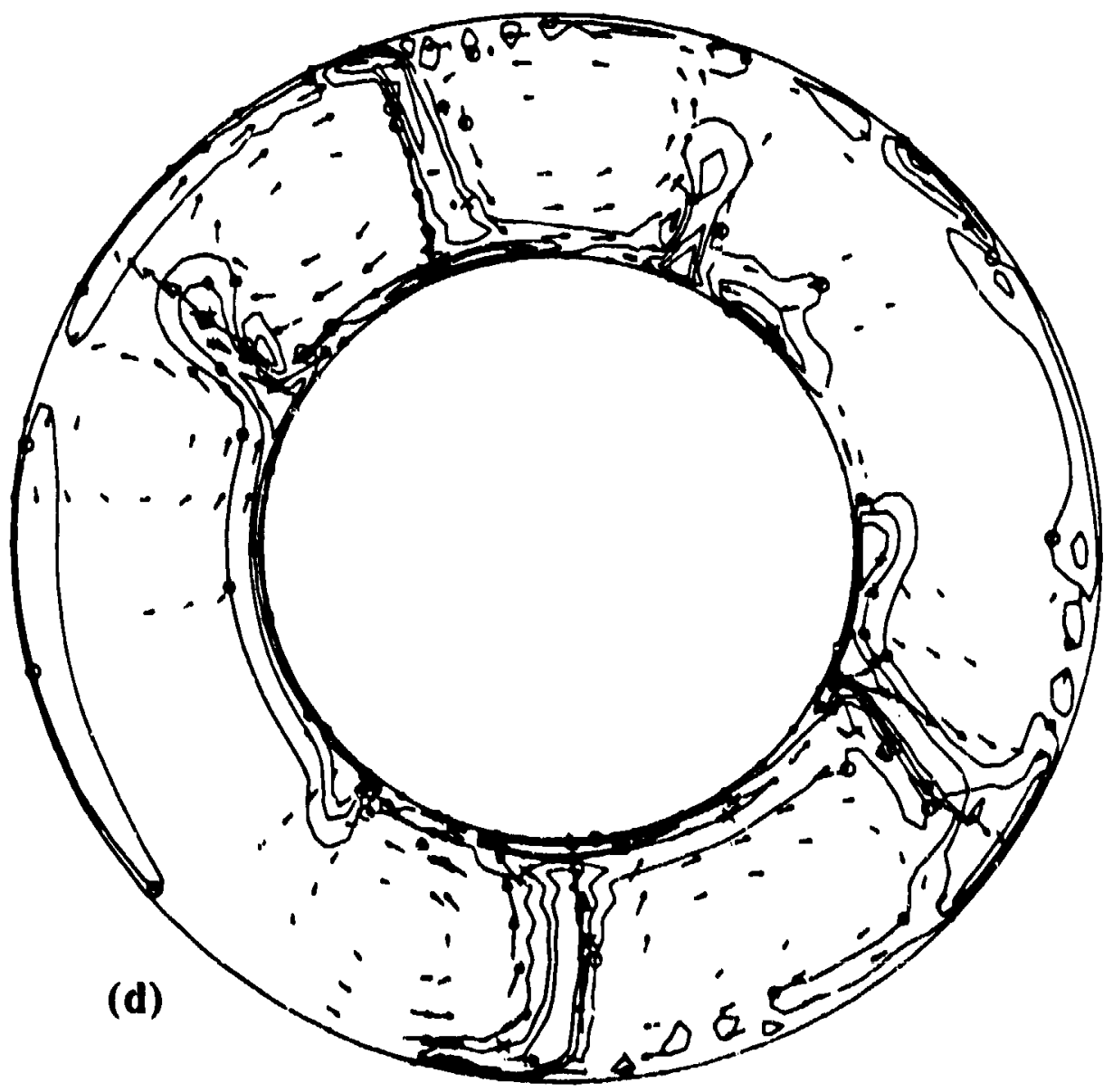

Figure 8. Continued. 


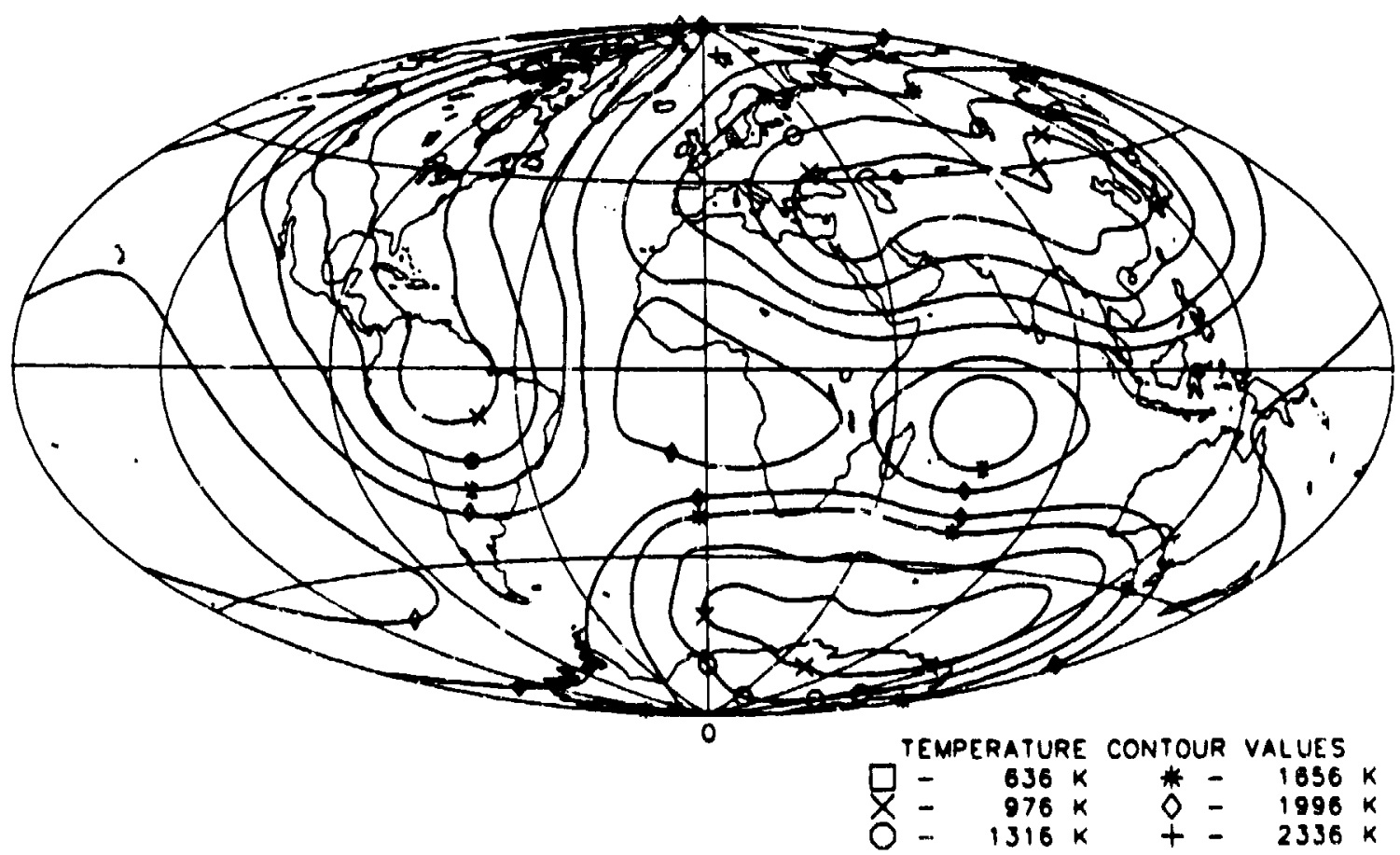

Figure 9. Temperature distribution at $2790 \mathrm{~km}$ depth at 60 Myr. Broad Inw temperature regions exist below the Americas, south central Asia, and the Antarctic region, and a conjunction of three high temperature belts occurs in the south Atlantic.

\section{References}

Baumgardner, J. R. (1983) A three-dimensional finite element model for mantle convection. Ph.D. thesis, UCLA.

Baumgardner, J. R. (1985) Three-dimensional treatment of convective flow in the earth's mantle. J. Stat. Phys. 39, 501-511.

Baumgardner, J. R. (1988) Application of supercomputers to 3.D mantle convection, in The Physics of the Planets, S. K. Runcom, ed., John Wiley and Sons. 199.231.

Baumgardner, J. R. and P. O. Frederickson (1985) lcosahedral discretization of the Iwo. sphere. SIAM J. Numer. Airal. 22, 1107.1115.

Bercovici, D., Schubert, G., and G. A. Olatzmaie: (1989a) Three-dimensional spherical models of convection in the earth's mantle. Science 244, 950-955.

Bercovici, D., Schulw:tr, G., and G. A. Glatzmeier (1989b) Influence of heating mode on three-dimensional collvection. Teophys. Res. Lett. 16, 617.620.

Chandrasekhar, S. (1961) Hydrodynamic and Hydromngnetic Stability. Clarendon Press, Oxford.

Chase, G. C. and D. R. Sprowl (1983) The modern geoid and ancient plake boundaries. Eyrth Planet. Sci. Lett. 62, 314-320. 
Christiansen, U. (1985) Thermal evolution models for the earth. J. Geophys. Res. 90, 29953007.

Clayton, R. W. and R. P. Comer (1983) A tomographic analysis of mantle heterogeneities from body wave travel tirnes (abstract). EOS Trans. AGU 62, 776.

Davies, G. F. (1988a) The role of the lithosphere in mantle convection. J. Geophys. Res. 93. $10451-10466$.

Davies, G. F. (1988b) Ocean bathymetry and mantle convection, 1, Large-scale flow and hotspots. J. G. Jphys. Res. 93, 10467-10480.

Dziewonski, A. M. (1984) Mapping the lower mantle: determination of lateral heterogeneity in P velocity up to degree and order 6. J. Geophys. Res. 89, 5929-5952.

Dziewonski, A. M. and J. H. Woodhouse (1987) Global images of the Earth's interior. Science 236, 37-48.

Gable, C. W., O'Connell, R. J., and B. J. Travis (1991) Convection in three dimensions with surface plates: generation of toroidal flow. J. Geophys. Res. 96, 8391-8405.

Glatzmaier, G. A. (1988) Numerical simulations of mantle convection: time-dependent, threedimensional, compressible, spherical shell. Geophys. Astrophys. Fluid Dyn. 43, 223-270.

Gurnis, M. (1988) Large-scale mantle convection and the aggregation and dispersal of supercontinents. Nature 332, 695-699.

Gurmis, M. (1990) Ridge spreading, subduction, and sea leve! fluctuations. Science 250. 970-972.

Gurnis, M. (1991) Continental flooding and mantle-tithosphere dynamics, in Sabadini et al., eds., Glacial Isostasy, Sea Level, and Mantle Rheology. Kluwer Publ., Dordrecht, Netherlands, 445.492.

Inoue, H., Fukao, Y., Tanabe, K., and Y. Ogata (1990) Whole mantle P-wave travel time tomography. Phys. Earth Planet. Int. 59, 294-328.

King, S. D., Gable, C. W., and S. A. Weinstein (1992) Models of convection-driven tectonic plases: a comparison of methods and results. Geophys. J. Int. 109, 481-487.

Peltier, W. R. (1985) Mantle convection and viscoelasticity. Ann. Rev. Fluid Mech. 17. 561.608.

Ramage, A. and A. J. Wathen (1992) Iterative solution techniques for finite element discretisations of fluid flow problems. Copper Mountain Conference on Iterative Met'iods Proceedings, Vol. 1.

Richards. M. A. and D. C. Engebretson (1992) Large-scale mantle convection and the history of subduction. Nature 355, 437.440.

Richards, M. A., Hager, B. H., and N. H. Sleep (1988) Dynnmically supported geoid highs over hotspots: observation and theory. J. Geophys. Res. 93. 7690-7708.

Weinstein, S. A., Olson, P. L., and D. A. Yuen (1992) Thermal convection with nonNewronian plates. Geophys. J. Int. (in press).

Zebib, A., Schubert, O. Dein, J. L. wid R. C. Paliwal (1983) Characier and stubility of axisymmetric thermal convection in spheres and spherical shells. Geophys. Astrophys. Fluid Dyn. 23, 1.42. 